УДК 551.5

\title{
СОВРЕМЕННЫЕ ИЗМЕНЕНИЯ КЛИМАТА И ИХ ПОСЛЕДСТВИЯ
}

\author{
Ю. П. Переведенцев \\ Казанский (Приволжский) федеральный университет, Россия \\ Поступила в редакиию 15 апреля 2019 г.
}

\begin{abstract}
Аннотация: В статье рассматриваются актуальные проблемы, связанные с глобальным потеплением климата. Приводятся документы, направленные на ограничение глобального потепления уровнем $1,5^{\circ} \mathrm{C}$. Дается краткая информация о четвертом совещании ведущих авторов специального доклада МГЭИК по океанам и криосфере в условиях изменяющегося климата, состоявшегося с 4 по 9 марта 2019 года в Казанском федеральном университете.
\end{abstract}

Ключевые слова: изменение климата, Межправительственная группа экспертов по изменению климата (МГЭИК), специальный доклад об океане и криосфере, ограничение потепления климата, риски.

\section{Current climate change and its effects Yu.P. Perevedentsev}

\begin{abstract}
The article discusses current problems associated with global warming. Documents aimed at limiting global warming to $1.5^{\circ} \mathrm{C}$ are given. A brief information is given on the fourth meeting of the leading authors of the IPCC special report on the oceans and cryosphere in a changing climate, held from 4 to 9 March 2019 in Kazan Federal University.
\end{abstract}

Key words: climate change, Intergovernmental Panel on Climate Change (IPCC), special report on the ocean and cryosphere, limiting climate warming, risks.

Проблема глобальных и региональных изменений окружающей среды и климата стала в настоящее время как никогда актуальной в связи с усиливающимся влиянием различных факторов антропогенного и естественного происхождения, среди которых солнечная активность, процессы происходящие в земной коре и ядре [3]. По современным представлениям, климат отражает физическое, химическое и биологическое состояние компонентов земной климатической системы (атмосферы, океана, суши, криосферы, биоты), поэтому для понимания его изменчивости необходима оценка динамики их параметров. Наиболее эффективным средством изучения происходящих сложных климатических процессов и их прогноза является математическое моделирование, результаты которого отражены в многочисленных отечественных и зарубежных публикациях. В последние годы, согласно [4], наблюдается естествен-

(С Переведенцев Ю.П., 2019 ный переход от моделей климата к моделям Земной системы, что позволило ввести в рассмотрение дополнительные геосферы-литосферу, гелиосферу и другие и дать описание более широкого круга физических, химических, биологических и антропогенных взаимодействий. Такого рода модели позволяют решать целый класс новых задач, связанных с проблемой деградации придонного слоя метаногидратов в Арктике, солнечно-земными связями, космической погодой и др. [4].

В Российской Федерации политика в области климата изложена в Климатической доктрине, утвержденной в 2009 году, которая определила основные направления развития нормативно-правовых, экономических и других инструментов, призванных обеспечить защиту государства от неблагоприятных последствий этих изменений и создать предпосылки для эффективного использования благоприятных возможностей, возникающих в связи с изменениями климата [7]. 
В 2012 году Всемирная метеорологическая организация сформировала глобальную рамочную основу для климатического обслуживания (ГРОКО), основной задачей которого является научное и информационно-аналитическое обеспечение адаптации экономики и населения стран к текущему и ожидаемому состоянию климатической системы, снижения риска стихийных бедствий [5]. Современное состояние проблемы климатических изменений отражено в последних оценочных докладах Межправительственной группы экспертов по изменению климата (МГЭИК) и Росгидромета, согласно которым в связи с возрастанием в атмосфере концентрации парниковых газов происходит непрерывный рост глобальной приповерхностной температуры, ожидающийся и в 21 веке $[1,11]$.

С целью сохранения климата планеты и в интересах обеспечения безопасности человека в декабре 2015 года были подписаны Парижские соглашения, направленные на ограничение выбросов парниковых газов в атмосферу, чтобы избежать повышения средней глобальной температуры воздуха на $2^{\circ} \mathrm{C}$ по сравнению с доиндустриальными уровнями (в настоящее время произошло повышение температуры почти на $1^{\circ} \mathrm{C}$, а концентрация углекислого газа в атмосфере достигла 404 млн $^{-1}$ ). Кроме роста температуры воздуха все чаще стали возникать экстремальные природные явления, наносящие значительный ущерб экономике и здоровью населения. Не случайно Международный экономический форум в Давосе (2017 г.) среди главных угроз на первое место поставил опасные гидрометеорологические явления. Обсуждение этих проблем было продолжено на Климатическом форуме в декабре 2018 года в Катовицах (Польша). Здесь шла речь о возможности ограничить глобальное потепление уровнем $1,5^{\circ} \mathrm{C}$.

Действительно, при ограничении глобального потепления уровнем $1,5^{\circ} \mathrm{C}$, по сравнению с потеплением на $2^{\circ} \mathrm{C}$, изменения в физических системах будут заметно меньше [3]. Это особенно коснется состояния Арктики, зон многолетней мерзлоты, скорости таяния Гренландского и Антарктического ледниковых покровов, повышения уровня Мирового океана. Уменьшатся риски, связанные с экстремальными осадками, засухами и нехваткой воды. Авторы Специального доклада МГЭИК «Глобальное потепление на $1,5^{\circ} \mathrm{C} »$, принятого 48-й сессией МГЭИК в октябре 2018 года в Инчхоне (Корея), считают, что реакция биологических систем будет более умеренная при потеплении на $1,5^{\circ} \mathrm{C}$ по сравнению с потеплением на $2^{\circ} \mathrm{C}$, что приведет к меньшему смещению ареалов некоторых биологических видов (насекомых, растений, позвоночных), вдвое меньшей территории трансформации экосистем.

Большое беспокойство вызывает увеличение кислотности верхнего слоя океана, деградации коралловых рифов, состояние морских организмов.

Этот доклад направлен на поиск путей смягчения изменения климата в контексте устойчивого развития. В нем, в частности, утверждается, что при потеплении на $1,5^{\circ} \mathrm{C}$ риски для природных и социально-экономических систем в целом больше, чем современные, но меньше чем при потеплении на $2{ }^{\circ} \mathrm{C}$ и более. Ограничение потепления в $\mathrm{XXI}$ веке уровнем $1,5^{\circ} \mathrm{C}$ потребует срочного (до 2030 г.) сокращения почти вполовину глобальной антропогенной нетто-эмиссии $\mathrm{CO}_{2}$ и доведение ее к середине века до нуля, что потребует ежегодных инвестиций сравнимых с $1 \%$ мирового ВВП [http://www.ipcc.ch/report/sr15/]. Объем доклада - более 300 станиц, краткое содержание которого представлено в [2].

В настоящее время ведется подготовка Шестого оценочного доклада МГЭИК об изменении климата 3-мя его рабочими группами. Первая группа работает над физическими основами науки об изменении климата, вторая - занимается последствиями изменения климата, адаптацией и уязвимостью, третья группа - вопросами смягчения во3действий изменения климата.

Рабочие группы экспертов регулярно собираются на совещания, цель которых состоит в подготовке как оценочных докладов (5 из них опубликовано в период 1990-2014 гг., 6-ой планируется завершить к 2022 г.), так и специальных (в частности, для лиц принимающих решения, - резюме для политиков).

Так, с 4 по 9 марта 2019 года по инициативе Росгидромета в Казанском федеральном университете состоялось Четвертое совещание ведущих авторов Специального доклада МГЭИК об океане и криосфере в условиях изменяющегося климата (СРОКК). Цель доклада - оценка последствий современных изменений климата на состояние океана, включая происходящие в нем биологические процессы, состояние многолетнемерзлотных материковых грунтов, полярных льдов и высокогорных ледников, сообществ людей, зависящих от них. В работе совещания приняли участие около 130 экспертов из 37 стран мира.

Выбор места проведения совещания не был случайным. В Казанском университете метеоро- 
логические наблюдения и климатические исследования ведутся с момента его образования (1804 г.). Здесь в 1812 году по инициативе профессора Ф. К. Броннера была образована одна из старейших в России Метеорологическая обсерватория. В Казанском университете в 1824-1829 годах активные метеорологические и магнитные исследования, при поддержке выдающихся естествоиспытателей того времени А. Гумбольдта, К. Гаусса и Д. Араго, проводил профессор А. Я. Купфер. По его инициативе в 1834 году была создана Метеорологическая служба России и основана в Петербурге Главная физическая обсерватория (ныне ГГО им. А. И. Воейкова). Еще одно знаменательное событие связано с историей Казанского университета: астроном и магнитолог И. М. Симонов (в будущем профессор, ректор) в 1819-1821 годах принял участие в кругосветной экспедиции Беллинсгаузена-Лазарева, открывшей 28 января 1820 года Антарктиду. В результате многолетних измерений им была опубликована в 1825 году статья «О разности температуры в Южном и Северном полушариях». Все это оказалось весьма символическим для нынешнего совещания - океаны и ледяные покровы были в поле зрения казанских ученых уже более 200 лет назад.

Результаты исследований Казанских климатологов за последние годы в области изучения изменений современного климата от поверхности Земли до уровня 0,1 гПа ( 64 км) представлены в работах [3, 6, 8-10, 12] в которых, в частности показано, что изменения температуры воздуха Северного полушария в период 1850-2016 годов испытывают неравномерный ход, определяемый 6070 - летним колебанием. Вклад глобальных процессов в изменчивость температуры для Приказанского региона зимой составил 37 , а летом $23 \%$, при этом, согласно расчетам по 7 моделям CMIP 5, в конце XXI века по наиболее жесткому сценарию 8.5 температура воздуха в Казани может повыситься в январе примерно на $8^{\circ} \mathrm{C}$, а в июле на $4^{\circ} \mathrm{C}$. В то же время вклад естественных факторов в будущие изменения температуры в Казани (до 2045 г.) оценивается значительно скромнее [10].

Современные информационно-вычислительные технологии и использование термодинамических параметров до уровня 64 км, позволили оценить скорость потепления в различных регионах Северного полушария в тропосфере и похолодания в стратосфере, характер взаимодействия между слоями атмосферы [12]. Важное внимание уделялось роли циркуляционных процессов в форми- ровании крупных аномалий в поле температуры и давления как на территории Северного полушария, так и в Приволжском федеральном округе [3].

Работа участников Четвертого совещания ведущих авторов СРОКК была весьма напряженной. 4 марта в Императорском актовом зале университета состоялось торжественное открытие совещания, участников которого приветствовали проректор по научной деятельности КФУ профессор Д. К. Нургалиев, первый заместитель премьер-министра Республики Татарстан Р. К. Нигматуллин, руководитель Росгидромета М.Е. Яковенко, министр экологии и природных ресурсов Республики Татарстан А. В. Шадриков. Перед открытием совещания в пресс-центре университета состоялась пресс-конференция. В ней участвовали со-председатель МГЭИК Ко БАРРЕТТ, со-председатель Рабочей группы I МГЭИК Валери Массон-Дельмотт, со-председатель Рабочей группы II МГЭИК Дебра Робертс и вице-председатель Рабочей группы II МГЭИК С. М. Семенов. Они представили анализ широкого круга проблем, связанных с программой работы совещания, по оценке последних научных знаний об основах физической науки об океанах и криосфере, о воздействии изменения климата на океан, прибрежные, полярные и горные экосистемы и сообщества людей, об оценке уязвимости и способности к адаптации.

Вечером первого дня совещания в «Корстоне» состоялся правительственный прием его участников. 5 марта состоялась встреча руководителей совещания со студентами и сотрудниками Казанского университета, где была дана подробная информация о деятельности МГЭИК по созданию Шестого оценочного доклада и по подготовке ряда специальных и методологических докладов, а также по широкому кругу актуальных проблем, связанных с активной фазой потепления современного климата и его влиянием на природные и социально-экономические системы. Лейтмотивом встречи была идея об ограничении роста глобальной температуры уровнем $1,5^{\circ} \mathrm{C}$ по отношению к доиндустриальным уровням. Встреча вызвала большой интерес не только у студентов-естественников, но и студентов института Международных отношений, которые расширили свой кругозор и имели возможность задавать вопросы на английском языке. Студентам было предложено участвовать в работе МГЭИК в качестве научных контрибьютеров различных уровней.

8 марта перед участниками совещания с краткими научными докладами выступили представи- 
тели от Российской Федерации: С. Ю. Селивановская, Ю.П. Переведенцев (КФУ), А. А. Екайкин (ААНИИ), С. С. Кутузов (ИГ РАН).

Совещание было проведено на высоком организационном и научном уровне. Его результаты послужат основой итогового варианта доклада, который будет рассмотрен на уровне правительств в период с 14 июня по 9 августа 2019 года. Затем правительства стран-членов МГЭИК рассмотрят Резюме для политиков СРОКК на 51-й сессии МГЭИК 20-23 сентября в Монако, и - в случае его одобрения - оно будет опубликовано на официальном сайте МГЭИК 25 сентября 2019 года.

Участники Совещания имели возможность о3накомиться с достопримечательностями столицы Татарстана - города Казани, с историей Казанского университета.

Они выразили глубокую благодарность Казанскому федеральному университету за гостеприимство и помощь в работе.

Статья подготовлена при частичной финансовой поддержке Российского фонда фундаментальных исследований, проекты 18-05-00721 и 18-45-160006.

\section{СПИСОК ЛИТЕРАТУРЫ}

1. Второй оценочный доклад Росгидромета об изменениях климата и их последствиях на территории Российской Федерации. - Москва : Росгидромет, 2014. -1008 с.

2. Гладильщикова А. А. Специальный доклад Межправительственной группы экспертов по изменению климата «Глобальное потепление на $1,5^{\circ} \mathrm{C}$ / А. А. Гладильщикова, Т. М. Дмитриева, С. М. Семенов // Фундаментальная и прикладная климатология. - 2018. - № 4. - C. 5-18.

3. Динамика тропосферы и стратосферы в умеренных широтах Северного полушария и современные изменения климата в Приволжском федеральном округе / Ю. П. Переведенцев [и др.]. - Казань : Издательство Казанского университета, 2017. - 186 c.

4. Дымников В. П. Моделирование земной системы / В. П. Дымников, В. Н. Лыкосов, Е. М. Володин // Труды VII Всероссийского метеорологического съезда. - Санкт-Петербург : D'ART, 2015. - C. 43-65.

5. Катцов В. М. Климатическое обслуживание в Российской федерации: вчера, сегодня, завтра / В. М. Катцов // Труды VII Всероссийского метеорологического съезда. - Санкт-Петербург : D'ART, 2015. C. 66-80.

6. Мониторинг и прогнозирование климатической изменчивости на территории Приволжского федерального округа / Ю. П. Переведенцев [и др.] // Гидрометеорологические исследования и прогнозы. - 2019. № 1(371). - C. 67-94.
7. Оценка макроэномических последствий изменений климата на территории Российской Федерации на период до 2030 г. и дальнейшую перспективу / под ред. В. М. Катцова, Б. Н. Порфирьева. - Москва : Главная геофизическая обсерватория, 2011. - 252 с.

9. Переведенцев Ю. П. Оценка современных изменений темпебратуры воздуха и скорости ветра в тропосфере Северного полушария / Ю. П. Переведенцев, К. М. Шанталинский // Метеорология и гидрология. 2014. - № 10. - C. 19-31.

9. Факторный анализ многолетней динамики глобального термического режима приземного слоя воздуха / М. А. Верещагин [и др.] // Известия РАН. Сер. географическая. - 2004. - № 5. - С. 32-41.

10. Шерстюков Б. Г. Дальние асинхронные связи в долгопериодных колебаниях климата Мирового океана и региональной атмосферы применительно к Республике Татарстан / Б. Г. Шерстюков, Ю. П. Переведенцев // Вестник Воронежского государственного университета. Сер. География. Геоэкология. - 2019. - № 1. - C. 5-11.

11. IPCC (2013). Climate Change 2013: The Physical Science Basis. Contribution of Working Group I to the Fifth Assessment Report of the Intergovernmental Panel on Climate Change / T. F. Stocker [et al.]. - Cambridge, United Kingdom; New York, USA. - 1535 p. - DOI: 10.1017/ CBO9781107415324.

12. Thermodynamic Parameter Variations in the Troposphere and Stratosphere in 1979-2016 / Y. P. Perevedentsev [et al.] // IOPConference Series : Earth and Environ-mental Science. - 2018. - Vol. 211, No. 1. Art: 012015.

\section{REFERENCES}

1. Vtoroy otsenochnyy doklad Rosgidrometa ob izmeneniyakh klimata i ikh posledstviyakh na territorii Rossiyskoy Federatsii. - Moskva : Rosgidromet, 2014. - 1008 s.

2. Gladil'shchikova A. A. Spetsial'nyy doklad Mezhpravitel'stvennoy gruppy ekspertov po izmeneniyu klimata "Global'noe poteplenie na $1,5^{\circ} \mathrm{S}$ " / A. A. Gladil'shchikova, T. M. Dmitrieva, S. M. Semenov // Fundamental'naya i prikladnaya klimatologiya. - 2018. № 4. - S. 5-18.

3. Dinamika troposfery i stratosfery v umerennykh shirotakh Severnogo polushariya i sovremennye izmeneniya klimata v Privolzhskom federal'nom okruge / Yu. P. Perevedentsev [i dr.]. - Kazan' : Izdatel'stvo Kazanskogo universiteta, 2017. - $186 \mathrm{~s}$.

4. Dymnikov V. P. Modelirovanie zemnoy sistemy / V. P. Dymnikov, V. N. Lykosov, E. M. Volodin // Trudy VII Vserossiyskogo meteorologicheskogo s"ezda. - Sankt-Peterburg: D'ART, 2015. - S. 43-65.

5. Kattsov V. M. Klimaticheskoe obsluzhivanie v Rossiyskoy federatsii: vchera, segodnya, zavtra / V. M. Kattsov // Trudy VII Vserossiyskogo meteorologicheskogo s"ezda. - Sankt-Peterburg : D'ART, 2015. - S. 66-80. 
6. Monitoring i prognozirovanie klimaticheskoy izmenchivosti na territorii Privolzhskogo federal'nogo okruga / Yu. P. Perevedentsev [i dr.] // Gidrometeorologicheskie issledovaniya i prognozy. - 2019. - № 1(371). - S. 67-94.

7. Otsenka makroenomicheskikh posledstviy izmeneniy klimata na territorii Rossiyskoy Federatsii na period do 2030 g. i dal'neyshuyu perspektivu / pod red. V. M. Kattsova, B. N. Porfir'eva. - Moskva : Glavnaya geofizicheskaya observatoriya, 2011. - $252 \mathrm{~s}$.

9. Perevedentsev Yu. P. Otsenka sovremennykh izmeneniy tempe6ratury vozdukha i skorosti vetra v troposfere Severnogo polushariya / Yu. P. Perevedentsev, K. M. Shantalinskiy // Meteorologiya i gidrologiya. - 2014. - № 10. - S. 19-31.

9. Faktornyy analiz mnogoletney dinamiki global'nogo termicheskogo rezhima prizemnogo sloya vozdukha / M. A. Vereshchagin [i dr.] // Izvestiya RAN. Ser. geograficheskaya. - 2004. - № 5. - S. 32-41.

\section{Переведенцев Юрий Петрович}

доктор географических наук, профессор, заведующий кафедрой метеорологии, климатологии и экологии атмосферы Института экологии и природопользования Казанского (Приволжского) федерального университета, г. Казань, E-mail: ypereved@pkfu.ru
10. Sherstyukov B. G. Dal'nie asinkhronnye svyazi v dolgoperiodnykh kolebaniyakh klimata Mirovogo okeana i regional'noy atmosfery primenitel'no k Respublike Tatarstan / B. G. Sherstyukov, Yu. P. Perevedentsev // Vestnik Voronezhskogo gosudarstvennogo universiteta. Ser. Geografiya. Geoekologiya. - 2019. - № 1. - S. 5-11.

11. IPCC (2013). Climate Change 2013: The Physical Science Basis. Contribution of Working Group I to the Fifth Assessment Report of the Intergovernmental Panel on Climate Change / T. F. Stocker [et al.]. - Cambridge, United Kingdom; New York, USA. - 1535 p. - DOI: 10.1017/ CBO9781107415324.

12. Thermodynamic Parameter Variations in the Troposphere and Stratosphere in 1979-2016 / Y. P. Perevedentsev [et al.] // IOP Conference Series : Earth and Environmental Science. - 2018. - Vol. 211, No. 1. - Art: 012015.

Perevedentsev Yuriy Petrovitch

Doctor of Geographical Sciences, Professor, Head of the Department of meteorology, climatology and atmosphere ecology, Institute of the Institute of Environmental Sciences, Kazan (Volga) Federal University, Kazan, E-mail: ypereved@pkfu.ru 